\title{
The starch from Solanum lycocarpum St. Hill. fruit is not a hypoglycemic agent
}

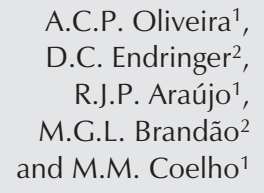

A.C.P. Oliveira ${ }^{1}$,

D.C. Endringer ${ }^{2}$,

R.J.P. Araújo ${ }^{1}$,

M.G.L. Brandão ${ }^{2}$

and M.M. Coelho ${ }^{1}$

\author{
Laboratórios de ${ }^{1}$ Farmacologia and ${ }^{2}$ Farmacognosia, \\ Faculdade de Farmácia, Universidade Federal de Minas Gerais, \\ Belo Horizonte, MG, Brasil
}

\section{Correspondence \\ M.M. Coelho \\ Laboratório de Farmacologia \\ Faculdade de Farmácia, UFMG \\ Av. Olegário Maciel, 2360 \\ 30180-112 Belo Horizonte, MG \\ Brasil \\ Fax: +55-31-3339-7666 \\ E-mail: mmcoelho@farmacia.ufmg.br \\ Research supported by CNPq \\ (No. 523281/95-1).}

Received May 25, 2002

Accepted January 6, 2003

\begin{abstract}
We have investigated the hypoglycemic effect induced by the starch obtained from the unripe fruits of Solanum lycocarpum (Solanaceae). Per os administration of the starch (1000 or $2000 \mathrm{mg} / \mathrm{kg}$, twice daily for 7 days, $\mathrm{N}=6$ ) did not change glycemia levels of nondiabetic female Swiss mice weighing 25-30 g. In streptozotocin-induced diabetic mice, similar treatment with the starch did not change the elevated glycemia $3 \mathrm{~h}$ after the last dose (diabetic treated with saline $=288 \pm 17$ / $309 \pm 18 ;$ starch $1000 \mathrm{mg} / \mathrm{kg}=295 \pm 33 ;$ starch $2000 \mathrm{mg} / \mathrm{kg}=258 \pm$ $37 ; \mathrm{N}=5$ ). In animals fasted for $15 \mathrm{~h}$, per os administration of glucose $(600 \mathrm{mg} / \mathrm{kg})$ significantly increased glycemia $1 \mathrm{~h}$ later. Previous (-30 $\mathrm{min}$ ) treatment of the animals with the starch (1000 or $2000 \mathrm{mg} / \mathrm{kg}$; N $=5$ ) did not change the increase of glycemia. Per os administration of the starch (1000 or $2000 \mathrm{mg} \mathrm{kg}^{-1}$ day $^{-1}$, twice daily for 7 days) did not induce body weight gain or loss. The chemical analysis of the starch indicated the presence of glycoalkaloids, a finding that represents a reason for concern since many of these substances are generally toxic. In interviews with 56 diabetic patients, 29 medicinal plants were reported as useful in their treatment of diabetes and S. lycocarpum was the sixth most frequently mentioned. All patients interviewed reported that they also used insulin or oral hypoglycemic drugs. The results of the present study do not provide evidence for a hypoglycemic effect associated with the polysaccharide fraction of S. lycocarpum in either normal or hyperglycemic mice. These data demonstrate the need for adequate pharmacological investigation of the natural products widely used in folk medicine.
\end{abstract}

Key words

- Solanum lycocarpum St. Hill.

- Glycoalkaloids

- Starch fraction

- Diabetes mellitus

- Hypoglycemic effect

$\ldots \ldots \ldots \ldots \ldots \ldots$.
Diabetes mellitus represents an important health problem in the world. Patients with type 1 diabetes are treated with insulin since the function of pancreatic $B$ cells is practically null. Type 2 diabetes is frequently characterized by a reduced production of insulin and also a low sensitivity of the tissues to this hormone. This form of diabetes is frequently treated with drugs that stimulate insulin release or the sensitivity of the tissues to this hormone, such as sulfonylureas, biguanides and thiazolidinediones. Despite the existence of different forms of insulin and many oral hypoglycemic drugs, the development of new drugs for the treatment of diabetes mellitus is needed, since its treatment is 
chronic and represents a high cost for the patient. Another important aspect is the high incidence of side effects associated with the use of some oral hypoglycemic drugs. Phenformin, one representative of the biguanides, although commercialized in Brazil, was withdrawn in many countries during the 1970's because of an association with lactic acidosis (1). Troglitazone, the first thiazolidinedione to be synthesized and used in the treatment of diabetes mellitus, has been withdrawn from the market in the United States because its use was associated with severe hepatic toxicity (2).

The Brazilian flora is one the world richest sources of bioactive material due to its biodiversity. Several plants are currently used in Brazilian traditional medicine to treat diabetes (3-5). The starch obtained from the unripe fruits of Solanum lycocarpum St. Hill. (Solanaceae) has been widely used and commercialized as a hypoglycemic agent in Brazil. Recently, Dall'Agnol and von Poser (6) carried out a chemical analysis of the starch and tried to correlate its supposed hypoglycemic activity with the polysaccharide content. However, these investigators did not conduct any experimental test to directly demonstrate the hypoglycemic effect attributed to the starch. As far as we know, no studies have evaluated the potential hypoglycemic effect of the starch of $S$. lycocarpum in experimental animals or the pattern of its use by a group of diabetic patients. In the present study, we evaluated both aspects.

Unripe fruits and branches with leaves and flowers of S. lycocarpum were collected in the State of Minas Gerais, Brazil. The plant was identified by J.R. Stehmann (Belo Horizonte Ciências Biológicas - BHCB, voucher specimen No. BHCB64921). The unripe fruits were peeled, cut into small pieces and submitted to turbolysis in water. The water extract was filtered and kept in a refrigerator for $24 \mathrm{~h}$ for starch precipitation. The starch was submitted to successive washings and filtrations until a clear white powder was obtained. The starch was dried at $105^{\circ} \mathrm{C}$ for $5 \mathrm{~min}$ and stored under refrigeration.

The starch of $S$. lycocarpum $(500 \mathrm{mg}$ ) was extracted with $6 \mathrm{ml}$ ethanol for $30 \mathrm{~min}$ at $95^{\circ} \mathrm{C}$, filtered and the solvent evaporated to dryness under reduced pressure. The residue was dissolved in $40 \mu \mathrm{l}$ of methanol. This material was submitted to silica gel thinlayer chromatography using chloroform: methanol (3:2) as a solvent system, followed by visual detection using Dragendorff's reagent and $10 \%$ sodium nitrite, the latter used to intensify the color of the spots. Solasodine (1\%) was used as a reference compound. The observed Rf's and the color of the spots were used to identify the steroidal alkaloids.

Female Swiss mice weighing 25-30 g were used to evaluate the potential hypoglycemic effect of the starch. The animals were maintained on a 12:12-h light-dark cycle, with food and water available ad libitum. The starch suspension was prepared in saline immediately before the experiments and administered per os in a volume of 100 $\mu 1 / 25 \mathrm{~g}$.

Two daily doses (8:00 and 18:00 h) of the starch $(1000$ or $2000 \mathrm{mg} / \mathrm{kg}$ ) were administered for 7 days and glycemia was determined $3 \mathrm{~h}$ after the last dose. The first dose of the starch was administered at 18:00 $\mathrm{h}$ on day 1 and the last dose at 8:00 h on day 7 . Food was removed immediately after the last dose. In parallel, on the last day, one experimental group was treated with one dose of glibenclamide (Teuto, Anápolis, GO, Brazil; $3 \mathrm{mg} / \mathrm{kg}$, per os) and glycemia was determined $3 \mathrm{~h}$ later.

To evaluate the effect of the starch on the glycemia of diabetic mice, $200 \mathrm{mg} / \mathrm{kg}$ streptozotocin was dissolved in sodium citrate buffer, $\mathrm{pH} 4.5$, and injected intraperitoneally. In this protocol, the animals were treated with two daily doses of the starch (1000 or $2000 \mathrm{mg} / \mathrm{kg}$ ) for 7 days, administered at 8:00 and 18:00 h, with the first dose administered $4 \mathrm{~h}$ after the treatment with streptozotocin. 
The first dose of the starch was administered at 18:00 h on day 1 and the last dose at 8:00 $\mathrm{h}$ on day 7 . Glycemia was determined $3 \mathrm{~h}$ after the last dose of the starch. In parallel, on the last day, an experimental group received a subcutaneous $(s c)$ injection of human NPH insulin (Biobrás S.A., Montes Claros, MG, Brazil; $1 \mathrm{U} / \mathrm{kg}$ ) and glycemia was determined $3 \mathrm{~h}$ later.

To evaluate the effect of the starch on the elevation of glycemia induced by oral administration of glucose, mice were fasted for $15 \mathrm{~h}$ before being treated with glucose $(600$ $\mathrm{mg} / \mathrm{kg}$, per os). The starch suspension was administered $30 \mathrm{~min}$ before glucose and glycemia was determined $3 \mathrm{~h}$ later.

The daily food consumption for each experimental group and body weight of each animal treated with the starch for 7 days were determined.

To determine glycemia, the animals were decapitated and blood was collected into tubes containing $\mathrm{Na}_{2}$ EDTA:NaF $(2: 1)$. Plasma glucose concentrations were determined by an enzymatic method (glucose oxidase and aminoantipyrine, Labtest kit, Lagoa Santa, MG, Brazil).

Data are reported as means $\pm \mathrm{SEM}$, with $\mathrm{N}=5-6$ animals in each group. Analysis of variance followed by the Newman-Keuls post hoc test was used to determine possible differences among the experimental groups related to glycemia or body weight, with the level of significance set at $\mathrm{P}<0.05$.

A questionnaire was applied to 56 diabetic patients at seven public Health Centers in Belo Horizonte, MG. The questionnaires provided information about sex, age, occupation, the medicines and medicinal plants used to treat diabetes, and how these were used. Clinical data were obtained from the medical records.

Initially, we evaluated the effect of one week treatment with the starch on the glycemia of nondiabetic mice, $3 \mathrm{~h}$ after the administration of the last dose. Glycemia was not significantly modified by treatment with the starch $(1000$ or $2000 \mathrm{mg} / \mathrm{kg}$, twice daily). However, glycemia was significantly reduced after administration of a single dose of glibenclamide ( $3 \mathrm{mg} / \mathrm{kg}$, per os) (Figure 1A).

We then investigated the effect of the starch on the glycemia of streptozotocininduced diabetic mice. As expected, animals treated with streptozotocin presented elevated glycemia. One week treatment with the starch (1000 or $2000 \mathrm{mg} / \mathrm{kg}$, twice daily) did not significantly reduce the glycemia of the animals. On the other hand, glycemia was significantly reduced after administration of a

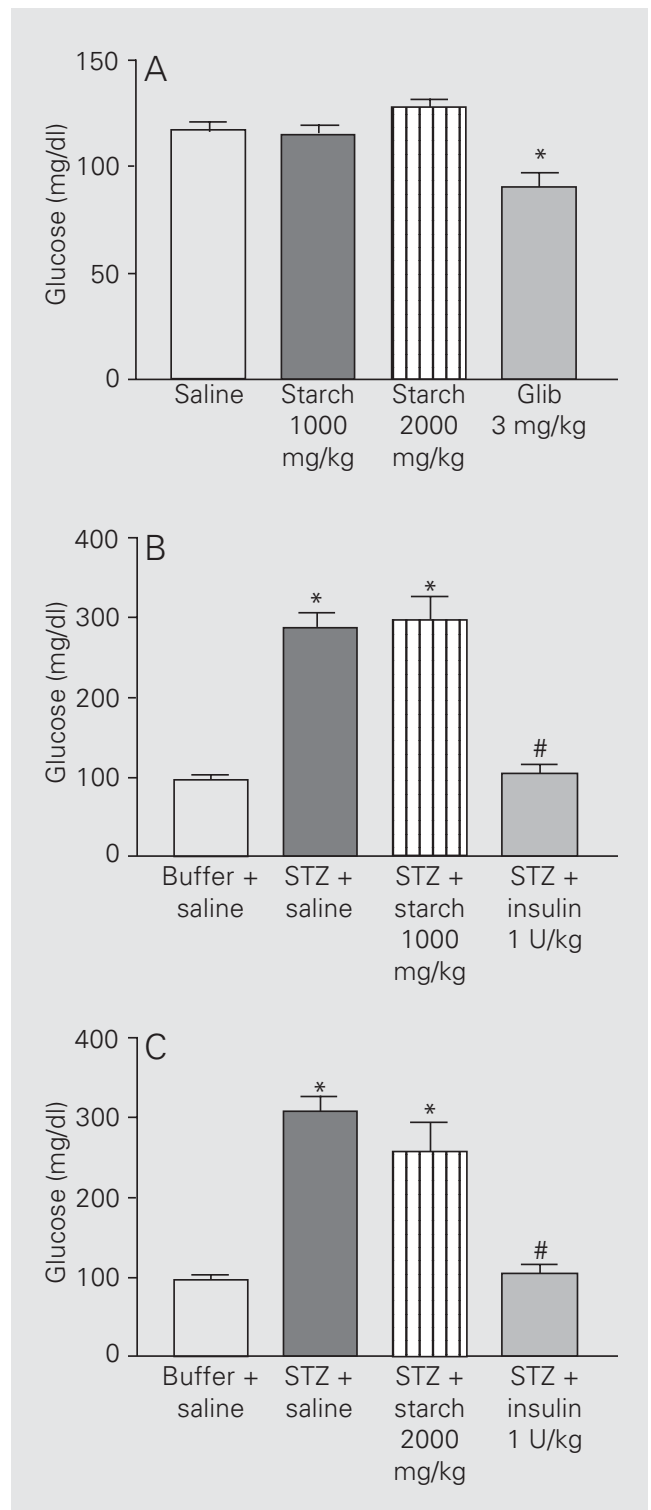

Figure 1. Effect of Solanum lycocarpum starch on the glycemia of nondiabetic and diabetic mice, measured $3 \mathrm{~h}$ after the last dose. $A$, Effect of the starch (1000 or $2000 \mathrm{mg} / \mathrm{kg}$, per os, twice daily for 7 days) on the glycemia of nondiabetic mice. Data are reported as means \pm SEM. One group was treated with a single dose of glibenclamide (Glib; $3 \mathrm{mg} / \mathrm{kg}$, per os) $3 \mathrm{~h}$ before. ${ }^{*} P<0.05$ compared to the group treated with saline ( $N=6$; ANOVA followed by the Newman-Keuls post hoc test). $B$, Effect of the starch $(1000 \mathrm{mg} /$ $\mathrm{kg}$ ) on the glycemia of mice with streptozotocin (STZ)-induced diabetes. One group was treated with a single dose of insulin $(1 \mathrm{U} / \mathrm{kg}, s c) 3 \mathrm{~h}$ before. ${ }^{*}, \# \mathrm{P}<0.05$ compared to the groups treated with buffer + saline or STZ + saline, respectively ( $N=5$; ANOVA followed by the Newman-Keuls post hoc test). C, Effect of the starch $(2000 \mathrm{mg} /$ $\mathrm{kg}$ ) on the glycemia of diabetic mice. One group was treated with a single dose of insulin (1 $\mathrm{U} / \mathrm{kg}, \mathrm{sc}) 3 \mathrm{~h}$ before. ${ }^{*},{ }^{\#} \mathrm{P}<0.05$ compared to the groups treated with buffer + saline or STZ + saline, respectively $(N=5$; ANOVA followed by the Newman-Keuls post hoc test). 
single dose of insulin $(1 \mathrm{U} / \mathrm{kg}, s c)$ (Figure 1B,C).

Since we did not observe a hypoglycemic effect of the starch in the previous protocols, we investigated whether the starch could reduce the absorption of glucose from the gastrointestinal tract. For this purpose, we administered glucose per os to fasted mice after treatment with the starch (1000 or 2000 $\mathrm{mg} / \mathrm{kg}$, per os). The per os administration of glucose induced an increase of glycemia that was not reduced in the animals treated with the starch (Figure 2).

The body weight gain of nondiabetic and diabetic mice treated with the starch (1000 or $2000 \mathrm{mg} / \mathrm{kg}$ ) for 7 days did not differ from that observed in the animals treated with saline. The food consumption of nondiabetic and diabetic mice treated with the starch (1000 or $2000 \mathrm{mg} / \mathrm{kg}$ ) for 7 days was reduced when compared to that observed for animals treated with saline. However, statistical analysis was not carried out because food consumption was determined for the group as a whole and not for individual animals.

Analysis of the residue obtained from the

Figure 2. Lack of effect of a single dose of Solanum lycocarpum starch on the glycemia of mice treated with glucose. Mice were fasted for $15 \mathrm{~h}$ and treated with glucose $(600 \mathrm{mg} / \mathrm{kg}$, per os) and glycemia was determined 3 h later. The starch (A, $1000 \mathrm{mg}$ or $\mathrm{B}, 2000 \mathrm{mg} / \mathrm{kg}$, per os) was administered 30 min before the treatment with glucose $(N=5)$. Data are reported as means \pm SEM.

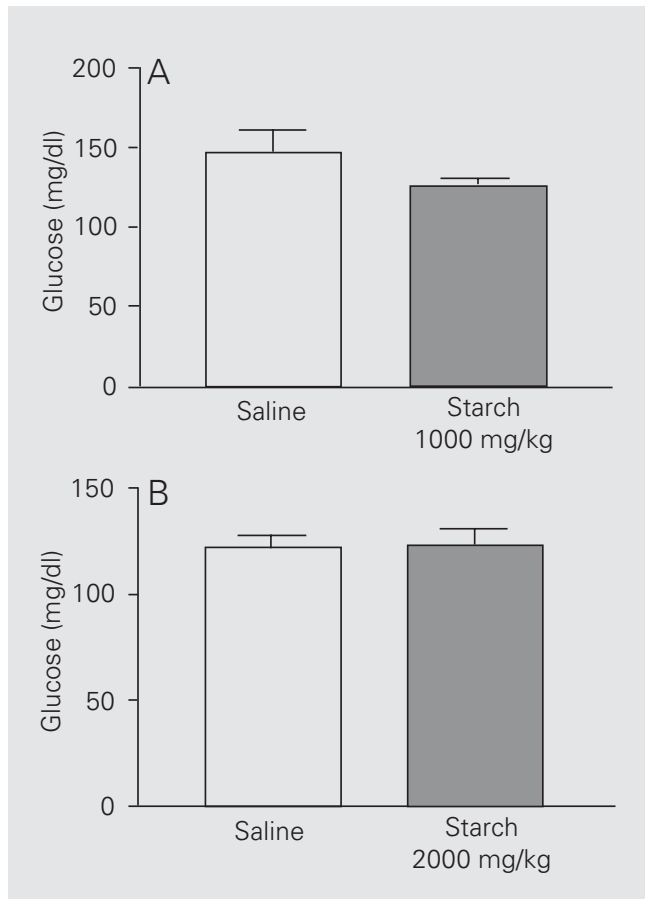

starch showed three brown spots (Rf's of $0.3,0.5$ and 0.7 , relative to solasodine) after treatment with Dragendorff's reagent and sodium nitrite. Solasodine presented a brown spot with an $\mathrm{Rf}$ of 0.8 . These results are suggestive of the presence of steroidal alkaloids in the starch of $S$. lycocarpum.

The questionnaires were answered by 56 diabetic patients (44 females and 12 males) with a mean age of 60.5 years. Analysis of the medical records and the medicines used by the patients indicated that 32 patients presented diabetes type 2, 15 patients presented diabetes type 1 , and 9 patients did not have a diagnosis at the time the interviews were carried out. Thirty-seven (66\%) patients reported the use of medicinal plants for treatment of diabetes. Twenty-nine medicinal plants were reported by the patients as useful to treat diabetes and the most frequently mentioned ones were Averhoa carambola L. (24 patients), Cissus sicyoides L. (20 patients), Baccharis trimera (Less.) DC. (13 patients), Bauhinia forficata Link (9 patients), and Anacardium occidentale L. (7 patients). The starch from $S$. lycocarpum was the sixth (6 patients) most used phytotherapic product. The survey also showed that all patients who reported the use of medicinal plants for the treatment of diabetes also used insulin or an oral hypoglycemic drug.

The starch obtained from the unripe fruits of $S$. lycocarpum has been widely used in Brazil as a hypoglycemic agent. It has been reported that some polysaccharides may reduce glycemia in experimental animals (7), a result that could support the use of the starch of $S$. lycocarpum as a hypoglycemic agent. However, the results of the present study did not provide any evidence for a hypoglycemic effect of the starch of $S$. lycocarpum in nondiabetic or in streptozotocin-induced diabetic mice. In addition, all patients interviewed who reported the use of medicinal plants, including the starch of $S$. lycocarpum, to treat diabetes also used an oral hypoglyce- 
mic agent or insulin.

Initially, we evaluated the effect of one week treatment with the starch on the glycemia of nondiabetic mice. Glycemia was not significantly changed by treatment with the starch (1000 or $2000 \mathrm{mg} / \mathrm{kg}$, twice daily). Whether higher doses could induce a hypoglycemic effect is not known, but administration of doses higher than $2000 \mathrm{mg} / \mathrm{kg}$ represents a problem because the starch suspension becomes too thick, impairing per os administration. However, glycemia was significantly reduced after per os administration of a single dose of glibenclamide. The hypoglycemic effect of the positive control, glibenclamide, a traditional oral hypoglycemic drug, is important because it demonstrates that under our experimental conditions it was possible to reduce the glycemia of nondiabetic animals.

It could be argued that a hypoglycemic effect of the starch would only be observed in diabetic animals. However, even in streptozotocin-induced diabetic mice, treatment with the starch did not reduce glycemia. A subcutaneous injection of insulin markedly reduced the glycemia, demonstrating once again that under our experimental conditions it was possible to reduce the glycemia of diabetic mice.

As the structure of the polysaccharides present in the starch has not been determined, we do not know if they are cleaved in the gastrointestinal tract or even if their components are absorbed. It has also been demonstrated that some polysaccharides slow gastric emptying, which in turn may slow the absorption of glucose and other nutrients (8). Taking this into consideration, we also investigated if the starch could reduce the absorption of glucose from the gastrointestinal tract, an event that could contribute to a hypoglycemic effect. However, the starch $(1000$ or $2000 \mathrm{mg} / \mathrm{kg})$ did not attenuate the elevation of the glycemia induced by per os administration of glucose in fasted mice.

Although the objective of the present study was not to carry out a toxicological investigation of $S$. lycocarpum starch, we observed that the animals treated with the starch ( 1000 or $2000 \mathrm{mg} / \mathrm{kg}$, twice daily for 7 days) did not differ from those treated with the vehicle in terms of body weight changes during the experimental period. A similar observation has been reported by Sá et al. (9). These investigators observed that treatment with the starch for 5 days did not induce body weight changes in rats or mice, although a significant weight loss was observed in the ventral prostate of mice. Casual observation of the animals treated with the starch also did not indicate that their general behavior differed from that presented by the animals treated with the vehicle. However, a preliminary chemical analysis of the starch indicated the presence of steroidal alkaloids. Although so far we have neither quantified these substances nor specifically identified them, the presence of steroidal alkaloids represents a reason for concern, mainly when one considers that a diabetic patient may permanently use a phytotherapic product containing such substances. Many studies carried out on experimental animals have shown that steroidal alkaloids are generally toxic. Baker et al. (10) have shown that Syrian hamsters orally treated with ground material obtained from Solanaceae species developed gastric and intestinal mucosal lesions. In addition, treatment of mice with steroidal alkaloids isolated from plants of this family also induced alterations of liver weight (11), arrhythmic beating in neonatal heart cells (12) and neural-tube defects (13).

Finally, we interviewed 56 diabetic patients who reported the use of medicinal plants for the treatment of diabetes at seven public Health Centers in Belo Horizonte, MG. Twelve patients reported the use of the starch of S. lycocarpum, the sixth most mentioned phytotherapic product, obtained from such different places as drugstores and herbal shops. Although the number of patients interviewed was small and no objective infor- 
mation was available about whether their pathological condition was being correctly treated, the most straightforward result of the interviews was that all patients who reported the use of medicinal plants also used an oral hypoglycemic agent or insulin as part of the treatment of diabetes. It should be emphasized that all the patients interviewed were attended at a Health Center and most of them had a correct diagnosis of diabetes, which may explain the fact that they were using a conventional hypoglycemic drug, insulin or an oral hypoglycemic agent.

To our knowledge, our study was the first to investigate the possible hypoglycemic effect of the starch in experimental animals and the pattern of its use by diabetic patients. Although the patients interviewed in our study are also using insulin or an oral hypoglycemic drug as part of their treatment, and thus probably obtain an adequate con- trol of their glycemia, we worry if many diabetic patients that are not adequately attended at a Health Center or by a health professional and are using a phytotherapic product as the sole mean to treat their condition attain the same objective. This possibility is a source of great concern because diabetes is a pathological condition associated with high morbidity and mortality. Taken together, the results of the present study point to the need for a careful evaluation of popular phytotherapic products both in the preclinical and clinical stages, even when they are widely used by the population.

\section{Acknowledgments}

We thank João Renato Stehmann, Department of Botany, Federal University of Minas Gerais, Belo Horizonte, MG, Brazil, for the identification of the plant.

\section{References}

1. Kolata GB (1979). The phenformin ban: is the drug an imminent hazard? Science, 203: 1094-1096.

2. Murphy EJ, Davern TJ, Shakil AO, Shick L, Masharani U, Chow H, Freise C, Lee WM \& Bass NM (2000). Troglitazone-induced fulminant hepatic failure: Acute Liver Failure Study Group. Digestive Diseases and Sciences, 45: 549-553.

3. Bragança LAR (1996). Plantas Medicinais Antidiabéticas. Editora Universidade Federal Fluminense (EDUFF), Niterói, RJ, Brazil.

4. Cruz GL (1982). Dicionário das Plantas Úteis do Brasil. Civilização Brasileira, Rio de Janeiro, RJ, Brazil.

5. Oliveira F \& Saito ML (1987/1989). Alguns vegetais brasileiros empregados no tratamento da diabetes. Revista Brasileira de Farmacognosia, 2-4: 170-196.

6. Dall'Agnol R \& von Poser GL (2000). The use of complex polysaccharides in the management of metabolic diseases: the case of Solanum lycocarpum fruits. Journal of Ethnopharmacology, 71: 337-341.

7. Tomoda M, Gonda R, Kasahara Y \& Hikino H (1986). Glycan structures of ganoderans B and C, hypoglycemic glycans of Ganoderma lucidum fruit bodies. Phytochemistry, 25: 2817-2820.

8. Spiller RC (1994). Pharmacology of dietary fiber. Pharmacology and Therapeutics, 62: 407-427.

9. Sá RCS, Vireque AA, Reis JEP \& Guerra MO (2000). Evaluation of the toxicity of Solanum lycocarpum in the reproductive system of male mice and rats. Journal of Ethnopharmacology, 73: 283-287.

10. Baker DC, Keeler RF \& Gaffield W (1989). Pathology in hamsters administered Solanum plant species that contain steroidal alkaloids. Toxicon, 27: 1331-1337.

11. Friedman M, Henika PR \& MacKey BE (1996). Feeding of potato, tomato and eggplant alkaloids affects food consumption and body and liver weights in mice. Journal of Nutrition, 126: 989-999.

12. Bergers WW \& Alink GM (1980). Toxic effect of the glycoalkaloids solanine and tomatine on cultured neonatal rat heart cells. Toxicology Letters, 6: 29-32.

13. Renwick JH, Claringbold WD, Earthy ME, Few JD \& McLean AC (1984). Neural-tube defects produced in Syrian hamsters by potato glycoalkaloids. Teratology, 30: 371-381. 